\title{
AUGUSTO COMTE E A SOCIALIZAÇÃO DO DIREITO.
}

\author{
Neste ano em que se comemora o primeiro centenário da morte \\ de Augusto Comte é oportuno focalizar a sua concepção do "di- \\ reito". Tanto mais oportuno se revela o tema quanto, com os regi- \\ mes de fôtça suscitados pelo totalitarismo em suas diversas moda- \\ lidades, tem modernamente havido quem sustente ser o direito mero \\ conceito metafísico, e, como tal, destinado a desaparecer (1).
}

(1). - Em Visão do Mundo Moderno, estudo publicado em 1934 numa revista de estudantes e reeditado pelo "Jornal do Comárçio" de 21 de fevereiro de 1954, Gilberto Amado escreve: "O Estado Soviético neǵa o direito baseando-se em Augusto Comte (através de todo o realismo jurídico contemporâneo)".

Do presente estudo, apoiado no conjunto da obra de Augusto Comte, torna-se evidente o eqüívoco em que laboram os que chegam à conclusāo de Gilberto Amado, porquanto o que Comte nega é tão só o direito concebido exclusivamente sob o prisma individual e absoluto, sem ser correlacionado com os deveres a que está sujeito o homem pelo simples fato de ser homem, segundo a fórmula de Terêncio que tanto entusiasmo inspirava a Santo Agostinho: "Homo sum: humani nihil a me alienum puto": "Sou homem e nada do que é humano considera alheio a mim".

Numa construção filosófi:a, como a de Augusto Comte, que se estendeu por quatro décadas, é essencial, aos que dela se abeiram, a estrita observân. cia do preceito lógico formulado por De Maistre: "nada mais importante do que julgar não por esta ou aquela frase de tal ou qual escritor, mas pelo conjunto e pelo espirito geral de sets trabalhos" (Vide "Du Pape", livro I, c. VIII) .

No terceiro volume do Sistema de Filosofia Positiva, tem o filósofo a nítida previsão do que seria o resultado prático dos sistemas totalitários nos quais sòmente se salientam os deveres do individuo sem que se the assegurem os direitos correspondentes: "Enquanto uns tendem involuntàriamente a reduzir tôdas as relações sociais a ignóveis coligações de interêsess privados, outros são arrastados, sem disto se darem conta, a or ßanizat uma espécie de mistificação universal, onde a pretensa dispasł̧̧ão permanente de cada qual dirigir seu procedimento de acôrdo com a idéta abstrata do dever, conduziria finalmente à exploração da espécie por um pequeno número de hábeis charLatäes".

No sexto volume da Filosofia Positiva, tratando diretamente do assunto, diz o filósofo, em poucas palavras, aquilo mesmo que Adolphe Franck posteriormente, e de modo magistral, explanaria no artigo - Direito - do seu "Dicionátio das Ciências Filosóficas", de que transcrevi alguns passos no texto da presente tese. Eis as palavras de Comte:

"Em geral a filosofia positiva tenderá, cada vea mais, a substituir espontâneamente, nos debates atuais, a discussāo vaga e tempestuơsa dos direitos pela determinação calma e rigorosa dos respectivos deveres. O primeiro ponto de vista, crítico e metafísico, teve de prevalecer enquanto a reaçāo negativa contra a antiga economia social não estava suficientemente completada; o segundo, ao contrário, essencialmente orgânico e positivo, deve, a seu turno, presidir à regeneraçāo final, porquanto um é, no fundo, puramente inciividual, e, o outro, diretamente social. Em vez de fazer consistir politicamente os deveres particulares no respeito dos direitos universais, serăo, ao revés, os direitos de cada qual concebidos como resultando dos deveres dos uutros para 
Adotem, ou não, explìcitamente êsse ponto de vista, esta é, de fato, a situação nos regimes de fôrça onde se tira aos homens tudo, até mesmo a mais cara de suas conquistas, aquela pela qual bendizia Tácito o tempo de Trajano, a saber, o direito de pensar cada qual como entende e dizer o que pensa

"rara temporum felicitate, ubi sentire quae velis et dicere quae licet" (2).

$\mathrm{O}$ que tem feito perigar o direito, tornando-o insustentável, é o modo absoluto e individualista, com que havia sido, até Augusto Comte, quase exclusivamente considerado.

Se todo ser vivo está na dependência do "meio cósmico": condições de temperatura, luminosidade, composição química do ar, humidade, eletricidade, pressão barométrica, etc., o homem, além dêsse meio cósmico ou planetário, subordina-se ainda ao "meio social" em que surge, isto é, à civilização em que se deserıvolve. Foi o que salientou José Bonifácio ao observar que Newton, nascido entre guaranis, seria apenas mais um bípede que pesaria sôbre a terra, sem chegar nunca a ser o grande matemático e astrônomo que se celebrizou, no século XVIII, em Inglaterra, onde dispôs dos elementos da imensa evolução científica, verificada desde os gregos até o seu tempo (3).

com êle: o que, sem dúvida, nạo é de nenhum modo eqüivalente. Esta dis. tinção geral representa alternativamente a preponderância social do espírito metafísico ou do espírito positivo: um conduzindo a uma moral quase passiva, na qual domina o egoísmo: e o outro levarido a uma moral profundamente ativa, dirigida pela caridade". (Vide "Filosofia Positiva", vol. VI, pgs. 454 e 4.55 da $4 a$. edição).

Para conhecer o pensamento de Comte sôbre o direito, é preciso ter-se em vista o coniunto de sua obra. e, especialmente, além dos textos citados, - "Catecismo Positivists", pgs. 350 e 351 da trad. portuguêsa de Miguel Lemos, 3a. edirão; o "Sistema de Política Positíva", vol. I, pgt. 151, 361-363: as "Novas Cartas Inéditas", pg. 30. Já é tempo de se fazer justiça a Augusto Comte e de se evitar, em relação a Positivismo, o mesmo que São Justino increpava aos rabinos do segundo século de nossa éra, relativamente ao Catolicismo: "Entre mil coisas boas que vos dizemos - advertia o glorioso mártir e doutor da Igreja - por uma pequenina que vos desagrade, ou não assimile:s, imediatamente da:s de mão a tudo o mais para vos apegardes apenas a essa pequenina palavra, fazendo-nos dela um crime, como as moscas que só pelas úlceras se deixam atrair". (Apud Abade Fleury: "Histoire Ecclé st-vitiatue", livro III, c. 66). Costumo, aludindo às obras de Corte, repetir as palavras de São Jerônimo a propósito da sua tradução de Isaías: “legant priys et posteo despiciant" _ "Teiam primeiro, compreendam primeiro, e depois desdenhern", porquanto, como adverte o grande Joseph De Maistre, "nenhum grau de talento e de espirito pode conferír, a quem quer que sefa, o direito de falar do que năo conhece". (Vide "Du Pape", livro II, Cł VIII).

Dizer-se que, baseado em Augusto Comte, o Estado Soviético nega o direito. corresponde a sustentar que, baseando-se em Comte, há quem adote o amor livre, quando se sabe irem as conviç̧ões monogâmicas do filósofo ao ponto de preconizar a viuvez eterna...

Consuitar-se-á com vantagem, sôbre a concepcão do direito em Augusto Comte, o belo livro de Lévy-Pruhl "La Philosophie Positive", pp. 376 e seguintes da 3a. ed.: Paris, Alcan, 1913

(2). - Tácito: Historiarem", I. I, c. 1.

(3). - Vide José Ponifácio: "Apontamentos para a civilizaçăo dos fndios", pg. 18 da ed. do Ministério da Agricultura, 1910. 
Com o decorrer da civilização, a dependência do homem, relativamente ao meio social, avoluma-se de tal modo que os pró prios fatôres físicos ou cósmicos só o afetam através da sociedade ou da espécie, porquanto esta the vai progressivamente modificando até as froprias condições de existência física, adaptando-lhe, cada vez mais, o planeta às conveniências. Tamanha é essa dependência do homem em relação à sociedade que pôde Augusto Comte escrever, com razão, nas "Conclusões Gerais" do "Sistema de Filosofia Positiva":

"o homem pròpriamente dito não é, no fundo, senão pura abstração: o que é real é a humanidade" (4).

Foi também o que proclamou o grande De Maistre a propósito da "Declaração dos Direitos do Homem":

"O homem isolado é uma entidade. Não há homem no mundo. Vi franceses, italianos, russos, etc. Mas, quanto ao homem, jamais o encontrei : se existe, não o conheço" (5).

Já Aristóteles fizera a mesma observação, afirmando que

“quem vive só, bastando-se a si mesmo, ou é Deus ou fera" (6),

e Marco Aurélio, alguns séculos mais tarde, assinalaria

"ser mais fácil encontrar um corpo terrestre separado da terra do que achar um homem que haja rompido todos os laços com a Humanidade" (7).

Foi o que sentiram os moralistas de todos os tempos, dos quais se fizeram eco, em épocas distantes e mui diversas, Lucano e Metastásio. O primeiro, num dos mais belos versos da poesia universal:

$$
\begin{aligned}
& \text { "Non sibi, sed toti genitum se credere mundo": } \\
& \text { "Crer-se nascido näo para si, mas para todo o mun- } \\
& \text { do" (8). }
\end{aligned}
$$

Quanto a Metastásio, todos the conhecem a cena $10 \mathrm{a}$. do $2 .^{\circ}$ ato da "Clemência de Tito":

\footnotetext{
(4). - Augusto Comte: "Filasofia Positiva", vol, Vr, pg. 590 da 4a. ed. e "Politica", vol. I, pg. 334 .

(5). - Joseph de Maistre: "Considérations sur la France", pg. 88 da ed. Nouvelle Librairie Nationale.

(6). - Aristóteles: "Politica", livro I, c. 1.0, § 12, pg. 9 da trad. de Barthélemy Satin-Hilaire, 3a. ed., Paris, 1874.

A tradução do pensamento aristotélico por mim adotada - "Deus ou fera" - é do Padre Antônio Vieira no sermão da 4a. Dominga da Quaresma, pg. 19 do vol. IV da ed. dos "Sermões", Lello e Irmão, 1907.

(7). - Marco Aurélio: "Pensamentos", 1. LX, 9, pg. 196 da trad. de Commelin.

(8). - Luçano - "Farsália", livro II, verso 373 .
} 
"Só che tutto è di tutti; e che ne pure

"Di nascer meritò chi d'esser nato

"Credo solo per se" (9).

"Sei que tudo é de todos; e nem sequer foi digno de nascer quem crê haver nascido só para si".

$\mathrm{E}$, de fato. S e o indivíduo não existe sòzinho, devendo tudo quanto é à sociedade em que surge e se desenvolve, como podem os seus "direitos" ser encarados, de modo absoluto, sob o prisma exclusivamente individual, sem se tomar em consideração a sociedade, da qual diretamente depende, desde que nasce, e sem a qual nada pode?

Isolado em sua ilha, valia-se o próprio Robinson dos ensinamentos acumulados pela série de gerações, que prepararam a civilização em que se formou, além dos materiais salvos do seu naufrágio, frutos multisseculares do trabalho coletivo, como ferramentas, armas, pólvora, preceitos de conservação dos alimentos, etc. Até mesmo aquêles que, como os anarquistas, se insurgem contra a sociedade e pretendem tudo considerar sob um prisma exclusivamente pessoal, negando o que devem aos contemporâneos, isto é, a "solidariedade", e o que devem às gerações anteriores, ou seja a "continuidade", só conseguem, na observação de Comte (10), proferir suas blasfêmias antissociais através de fórmulas decorren. tes da ccoperação de longa série de gerações, porquanto a linguagem articulada é uma construção eminentemente coletiva, e, daí não a possuirem os animais, mesmo superiores, visto não chegarem a constituir sociedades regulares, nas quais, ao lado da "solidariedade", se encontre a "continuidade".

Se, portanto, o homem surge e vive em sociedade, dela recebendo imensos benefícios, sem poder jamais retribuir-lhos no mesmo grau, por maior que seja o seu valor, os seus direitos sòmente podem ser concebidos em relação a essa mesma sociedade, que the garante a existência, resultando os "direitos" de cada um dos deveres dos outros para com êle, e vice-versa. Assim, pois, em lugar da discussão vaga e tempestuosa dos "direitos", considerados de modo absoluto, sob o prisma puramente individual, há de fazer-se a determinação calma e rigorosa dos "deveres" de cada qual, entendendo-se por "dever" o concurso que a sociedade exige de cada um de seus membros ao fazê-lo subordinar seus interêsses pessoais, exclusivamente egoísticos, ao bem geral. Nesta concepção, em que prevalece o prisma social sôbre o individual e o relativo sôbre o absoluto, torna-se o "direito" a "garantia" que a Sociedade dá a ca-

(9). - Metastácio: "Drammi Scelti", pg. 59 da ed. de Paris, 1852. Comparar com Aristóteles, livro VIII, c. $1 .^{0}$ da "Política".

(10). - Augusto Comte: "Sistema de Política Positiva, vol. I, pg. 221. 
da ser humano para o cumprimento integral de seus deveres, de modo a cooperar cada qual para a maior felicidade coletiva.

Tal é, como se sabe, o ponto de vista vitoriosamente defendido por Augusto Comte e sua escola, e seguido por Duguit, Josserand, Sotelo e muitos outros publicistas modernos, entre os quais se infileira a figura respeitável de Ihering ao sustentar que

"ao egoismo individual tem a sociedade o' direito, que é também um rever, de opor o sen próprio interêsse. $E$ o interêsse da sociedade nấo é sómente o que serve ao individuo, mas o que é útil à coletividade e garante a existência de todos. Nisto está a Justiça. Esta última paira acima da liberdade. Cada homem existe nấo sómente para si, mas também para o mundo; eis porque a liberdade, o que convém ao indivíduo, deve ser subordinado à Justiça, que é o que convém a todos" (11).

O justo, o

"Direito - disserta, nesta mesma corrente de idéias, Elias Regnault - "é o que os homens sancionaram através do seu assentimento. Dai resulta não haver "Direito" anterior à Sociedade, nem fora dela, não sendo os "Direitos" do homem senão os Direitos sancionados pela Sociedade, assim como os seus deveres são as regras também prescritas pela Sociedade. Quanto ao Direito inddividual - não existe; porquanto o homem só possui direitos, como indivíduo, por ser uma fração do todo social. Não reconhecemos, portanto, um pretenso Direito natural, no qual o homem, desprovido de deveres, gozaria da sua liberdade e independência primitivas. Jamais houve, para o homem, outro estado ide natureza diverso do estado de sociedade. Não porleria, portanto, haver para êle outro Direito natural senão o Direito Social” (12) .

Sem que o declarasse expressamente, fêz, por outro lado, Adolphe Franck no artigo "Direito" de seu "Dicionário das Ciências Filosóficas", o mais lúcido comentário da concepção de Augusto Comte a respeito. Ei-lo:

"Pode-se fazer compreender a idéia de "direito" pela de "dever", da qual é inseparável e com a qual forma, em nosso espírito, uma correlação inseparável. Queremos dizer que nã̃o há deveres sem direitos, nem direitos sem deveres, sendo impossivel conceber uma dessas noções sem a outra, ambas encerradas na idéia superior de lei moral. A esta própria lei, ora damos o nome de direito,

\footnotetext{
(11). - Apud Arnoldo Medeiros da Fonseca, aula sôbre o contrato do trabalho, ci. tada por Edmundo Lins Neto na monografia: "Qual o conceito de abuso de direito que melhor se ajusta ao direito positivo brasileiro", in " $A$ Epoca", junho e julho de 1942, pg. 26 .

(12). - Elias Regnault, artigo "Droit" do "Dictionnaite Politique" publicado por Duclerc e Pagnerre, 3a. ed., Paris, 1848.
} 
ora o de dever, segundo o prisma sob o qual a encaramos, a saber, conforme o seu objeto, isto é, o homem, é considerado como passivo ou como ativo em relação a seus semelhantes. Com efeito, o que a lei moral me determina fazer, o que ela me prescreve como um dever, proibe, ao mesmo tempo, aos outros que mo impeçam ou me oferecam obstáculos por qualquer meio que seja. Ela me declara, por conseguinte, inviolável no uso que faço de minhas faculdades para obedecer-lhe; e esta inviolabilidade de que me revisto, ou essa proibição feita a meus semelhantes, eis precisamente o que constitui o meu "direito". Este princípio não carece de demonstração; brilha, pela sua própria evidência, como um axioma geométrico; é um axioma moral que ninguém poderia negar sem, ao mesmo tempo, negar tôda idéia de justiça e de obrigação reciproca. A conseqüência que imediatamente daí decorre é que o caráter moral do homem, os deveres que êle tem de preencher, o caráter universal dêsses deveres, constituem o fundamento único de todos os seus direitos... A proposição de Hobbes, segundo a qual o homem, no estado de natureza, tem direito a tôdas as coisas, é absolutamente destituída de sentido. No estado de natureza, tal qual o compreende o filósofo inglês, isto é, na ausência de tốda lei e de tôda obrigação, nenhum direito pode ser admitido, porquanto só há lugar para a fôrça... Assim, pois, não há meio têrmo: ou temos de renunciar a qualquer espécie de direito, e dizer que o homem, apesar das faculdades admiráveis de que o dotou a natureza, não é senão uma coisa à mercê de quem dela quiser, ou puder apropriar-se; ou temos de almitir serem os nossos direitos fundados sôbre os nossos deveres, só existindo no limite dêsses mesmos deveres... Não há direito ou poder sem condição, nem liberdade sem limites. Estes limites não são arbitrários, mas determinados a priori, de modo invariável, pela própria i:déia do direito. Porquanto, desde que os mesmos direitos (referimo-nos aos direitos naturais) pertencem indistintamente a todos os homens, os direitos de um não poderiam ir até ao ponto de ofender os direitos dos demais; o que é sagrado para um, é sagrado para todos. Assim, a liberdade de comunicar o meu pensamento não pode estender-se até o direito de caluniar, difamar os meus semelhantes, nem instigá-los, uns contra os outros, a atos de violência, ou corromper almas indefesas. A ninguém é permitido (quer seja uma corporacão, quer um indivíduo), sob o pretexto de usar da sua liberdade de consciência, perturbar a consciência e a liberdade dos outros, ou colocar-se fora das condições sôbre as nuais repousa a liberdade omum. Não devo, enfim, qualquer respeito à vida de quem injustamente ataca a minha, e ninguém ousaria invocar a liberdade individual para um fím de violência ou rapina" (13).

(13). - Adolphe Franck, artgio "Droit" do "Dictionnaire des Sciences Philosophiques", pgs. 411,412 e 413 da 2a. edição, Paris, Hachette, 1875. 
O "direito" deixa de ser, assim, um atributo ou faculdade inerente apenas ao indivíduos, para ser, acima de tudo, uma função social. Este o conceito que hodiernamente tende a prevalecer na generalidade dos espíritos, como média das duas tendências que, a partir de fins do primeiro quartel dêste sofredor século $X X$, tem dividido o mundo político: a do individualismo e a do totalitarismo. Enquanto a corrente individualista desconhece a subordinação necessária do individuo à sociedade, os regimes totalitários, ao revés, qualquer que seja o tipo de suas respectivas ideologias, esmagam o inđivíduo e o transformam em mero autômato explorado pelos charlatães que pretendem representar os interêsses sociais. Só salientando o concurso exigido pela comunidade, desconhecem êsss regimes a imprescindível independência e dignidade da pessoa humana. Decorre esta tendência de desconhecerem os sistemas totalitários a separação dos dois poderes - "espiritual e temporal" - uma das mais belas conquistas que a civilização deve ao $\mathbf{C a}$ tolicismo, e sem a qual não há dignidade humana, como é fácil evidenciar através de rápido esfôrço histórico.

Nenhuma sociedade, por mais rudimentar, subsiste sem um govêrno, isto é, um órgão de reação do conjunto sôbre as partes, vale dizer, da coletividade sôbre os indivíduos. Esse govêrno ou direção da sociedade pode ser "político ou material", atinente à ação sôbre a "terra", e "espiritual" ou "moral", concernente à ação sôbre o próprio "homem". Preocupa-se o primeiro com os atos dos indivíduos, tendo; como sanção, a fôtça, e, o segundo, com os senmentos e idéias, servindo-lhe de sanção, só e exclusivamente a "opinião". Numa palavra: o poder político disciplina as "ações", e, o espiritual, as "vontades", representando, portanto, a reação da inteligência sôbre a fôrça. Sendo o govêrno dos atos de influência menos profunda e duradoura do que o dos pensamentos e afeições, é também chamado "temporal". Achavam-se, na Antigüidade, intimamente entrelaçados êsses dois poderes, mesclando-se sempre 0 conselho ou persuasão, peculiar ao poder espiritual, com a "ordem" ou "mando", que é particular do poder temporal. Nada mais espontâneo, aliás, do que essa primitiva confusão, porquanto, diz o provérbio, "quem pode, não pede", oferecendo real vantagem para a disciplina dos exércitos antigos, essa dupla atribuição dos chefes militares, os quais ora se apresentavam como pontífices, ora como guerreiros.

Estava, por conseguinte, na Antigüidade, a moral ìntimamente ligada e subordinada à política. Em Roma, fazia o censor regulamentos sôbre o luxo e as despesas dos cidadãos, a maneira pela qual se deviam vestir, etc. Nada mais arbitrário e ofensivo à dignidade humana do que essa interferência pueril, e, freqüentemente mesqui- 
nha, através da qual o magistrado, entre os gregos e romanos, tendia a sujeitar a vida particular a minuciosa regulamentação, quase sempre ilusória, e, muitas vêzes, mero pretexto para odiosas perseguições. Ficou famoso, nos fastos de Roma, o caso de Manílio, já designado cônsul pelo povo, e, entretanto expulso do Senado por influência de Catão, visto haver beijado sua mulher, perante uma de suas filhas. Em Esparta costumavam os éforos determinar que os cidadãos raspassem o bigode, e, em Atenas, proibia uma lei de Péricles o casamento dos cidadãos com estrangeiras (14).

Não só entre os gregos e romanos interferia o Estado-Pontífice na vida íntima e até na consciência dos cidadãos. E' o característico de tôdas as civilizações incipientes, como o provam as teocracias incas e astecas. Daí chamar Comte "retrogradação" à tendência totalitária de absorção do poder espiritual pelo temporal (15).

Como instituição política, a "liberdade espiritual", "de pensamento ou de consciência", consiste em não se coagir ninguém, "materialmente", a seguir qualquer opinião e sentimento, e, bem assim, em não se impedir que manifeste, de forma pacífica, o seu pensamento e modo de sentir. Refiro-me à manifestação pacífica do pensamento e dos sentimentos, e não à incitação de atos violentos contra as coisas e as pessoas, que o Govêrno Temporal, está não só no direito, mas ainda no dever de reprimir e até de prevenir.

Essa noção de haver um campo, que se subtrai à ingerência do Govêrno Temporal, como o das idéias e sentimentos, foi esboçada pelos gregos, como se vê da "Antígona" de Sófocles. No famoso diálogo entre Creonte e sua sobrinha, a propósito de haver esta, infringido as leis do primeiro, enterrado seu irmão Polinices, diz a heroina:

"Essas leis não foi Zeus quem as fêz, nem a Justiça, que tem assento entre os Deuses subterrâneos. E não acreditei pudessem os teus éditos ter mais fôrça do que as leis não escritas e imutáveis dos Deuses, porquanto não és senão um mortal. Não é de hoje, nem de ontem, que elas são imutáveis; mas, eternamente poderosas, ninguém sabe a partir de quando passaram a vigorar" (16) .

Só o Catolicismo, porém, apresentou a seperação dos dois poderes - temporal e espiritual - como programa, embora a natureza absoluta do seu dogma o levasse, depois de sua vitória, a aspirar à teocracia, como são exemplos típicos, entre outros, Gregório VII e Inocêncio III, e mesmo o grande São Bernardo, em suas "Conside-

\footnotetext{
(14). - Vide Plutarco: "Vida de Manco Catão", t. II, pg. 250 da trad. de Pierron; Tácito: "Anais", livro II, c. 33; Cícero: "De legibus", III, 3; Auliu-Gélio, li. vro I, 6; Valério Máximo, II, 9; Plutarco: "Vida de Age e Cleómenes", t. IV, pg. 136 da trad. cit.; Barthélemy: "Voyage du jeune Anachersis", t. II, p. 205 da ed. Hachette.

(15). - Vide Marius André: "Bolivar et la Democratie", pg. 171, Paris, 1924.

(16). - Sófocles: "Antígona", pg. 249 da trad. de Leconte de Lisle, Paris, Lemerre.
} 
rações sôbre os heréticos", onde adota a opinião de Santo Agostinho de

\author{
"ser melhor queimarem-se alguns homens neste mun- \\ do do que todos no outro"... (17).
}

A noção de "tolerância" é uma noção eminentemente moderna. Platão, em sua "República" não admitia cidadãos que não participascrem da religião do estado, mandando-os prender no "sophronistério", isto é, na "casa em que os homens tomam juízo", designando êste eufemismo nada menos do que o cárcere! Tal também o parecer de Cícero, apesar de não crer nos deuses, e dêsse epicurista, amigo de Virgílio e Horácio, protetor das letras e artes - Mecenas (18).

Foram os cristãos os primeiros a pleitear e defender de modo explícito a tolerância, e, conseqüentemente, a separação dos dois poderes, conforme se vê em Tertuliano e Lactâncio, morrendo os mártires cristãos na defesa do mais sagrado dos direitos: o da liberdade de pensamento, através da qual lançaram as bases da verdadeira independência e grandeza do homem, conforme salienta Boissier.

A inquisição e as guerras religiosas, como a dos albigenses, constituiram lamentáveis aberrações de uma das mais belas conquistas do próprio Catolicismo, o qual, como excelentemente escreve o Cardeal Cerejeira,

"criou o individuo moderno, dando-lhe, com a consciência da sua autonomia moral, a noção precisa dos seus direitos, a dignidade e o respeito, que lhe é devido, com o ldesenvolvimento da vida interior, como germe de todo o progresso social. E' preciso até avançar mais, com Augusto Comte: deve-se ao Catolicismo a existência dum poder moral independente do Estado, que garante o respeito da pessoa humana, e, por conseguinte, a limitação do Estado, o qual, à medida que se desenvolve, tende sempre a reger tôda a vida do homem (o que seria o mesmo que submetê-la inteiramente ao regime da fôrça e, portanto, matar a liberdade de consciência)" (19).

$\mathrm{Na}$ Antigüidade, não se havia ainda chegado, nìtidamente, à concepção de humanidade, isto é, de uma única espécie, habitando o mesmo planeta, de modo a poder considerar-se o homem, por tôda parte, "o cidadão e o cultor da terra inteira". Era a Pátria a suprema noção social, o que fazia com que os cidadãos das diversas pátrias procurassem obter o predomínio da sua sôbre as demais, e, daí,

(17). - Vide Abade Vacandard: "Vie de Saint Bernard", t. II, p. 476 e 478 da ed. de Paris, 1927 e Gibbon: "The Decline and Fall of the Roman Empire", c. XXXIII, pg. 548 da ed. de Londres, 1836 .

(18). - Vide Boissier: "La fin du paganisme", t. 1.0, pg. 45 da $5 a$. ed.; Cicero: "De leģibus", livro II, c. 8; Diāo Cássio: "História Romana", livro III, c. 36.

(19). - Cardeal Cerejeira: "A Idade Média", pgs. 201 e 208 da ed. de 1936. 
ser a Moral, a qual considera o bem da espécie em seu conjunto, subordinada, entre os antigos, à Política, isto é, aos interêsses de cada pátria.

" probidade e a justiça dos antigos - observa Chateaubriand no "Gênio do Cristianismo" - eram relativas à pátria e não iam além de seus respectivos limites" (20).

Conseguindo fundir, numa pátria única, quase tôdas as nações antigas, permitiu a incorporação romana que se esboçasse, claramente, a concepção de humanidade substituindo-se os laços políticos, que ligavam os diferentes povos do Império, por vínculos espirituais, quando a própria extensão da conquista romana lhes tornou inevitável a desagregação política. Surgiu, assim, no seio do incomparável império, a universal aspiração a um sistema de concórdia em que o amor de todos os homens servisse de base a um sistema de crenças e sentimentos comuns. E a concretização dêsse anelo foi - Catolicismo, que se propôs a regrar, moralmente, fôrças que não mais podiam sê-lo apenas cìvicamente, instituindo destarte a separação dos dois poderes.

Esmagando, porém, o indivíduo, até mesmo em seu fôro íntimo, transformando-o em mero autômato, sem consciência, nem dignidade pessoal, e, bem assim hipertrofiando o nacionalismo, como se, acima da pátria, não pairasse a Humanidade, ou seja a pátria comum para a qual tôdas as demais convergem, representam os regimes totalitários a mais perigosa das retrogradações modernas, que cumpre aos intelectuais, que não quiserem incidir na trahison des clerc, combater, vulgarizando as verdadeiras noções da sociologia e da história.

Relativar e socializar o conceito de "direito", considerando-o sob o prisma, não "individual" e "absoluto", mas "social", e, portanto, "relativo", mostrando a permanente subordinação do indivíduo à sociedade, à qual tudo deve e da qual em tudo depende, eis o único meio de resguardar-se o conteúdo do direito lapidarmente formulado por Ulpiano:

"Juris praecepta sunt haec - honeste vivere, alte. rum non laedere, suum cuique tribuere" (21).

Coerente com a sua tese, sustentava Augusto Comte que inclusive o mais característico dos direitos, aquêle cuja essência, no dizer dos tratadistas, como Coelho da Rocha, é ser livre e exclusivo em seu exercício - o de propriedade - em vez de ser uma prerrogativa individual, não passa de elevada função social, destinada a

(20). - Chateaubriand: "Génie du Christianisme", 4a. Partie, c. 13 do livro II, pg. (21). - Ulpiano - "Digesto", 1. I, frag. 10, 3 . 
formar e administrar os capitais através dos quais cada geração facilita a sua própria existência e minora os trabalhos da geração seguinte.

A convergência dos esforços em qualquer atividade coletiva exige indivíduos, que, de modo exclusivo, se apliquem à função de coordenar, dirigir e orientar as atividades dos demais. Esse indispensáveis coordenadores passam a ser os depositários ou gestores do capital produzido pelos que trabalham sob a sua direção, só devendo possuí-lo - na expressão do admirável São Paulo - como se o não possuissem - tanquam non (22).

Esta socialização do direito de propriedade é, aliás, a mesma que se verificava, na Idade Média, com os "feudos", nos quais o vassalo "detinha", mas não "possuia" a respectiva propriedade. Estendendo-se por tôda a sociedade, existia então complicado sistema de sub-feudos, em virtude do qual tôda posse (tenure) era condicionada ao cumprimento de determinadas obrigaçōes sociais. Ao faltar ao cumprimento dessas obrigações, podia o vassalo ser despojado do que detinha (23).

Sendo o capital social em sua origem, também tem de sê-lo em seu destino, consistindo, segundo Augusto Comte, a grande questão entre o "Capital" e o "Trabalho", não em se destruir o primeiro, o que seria quimérico à vista das leis naturais a que estão sujeitos o homem e a sociedade, mas em regulá-lo de modo a ter, dia a dia mais, a aplicação social que lhe impõe a sua origem.

$\mathrm{Na}$ fortuna mais honestamente adquirida, é sempre insignificante a parte do indivíduo, quando comparada com o contingente dos seus contemporâneos e das gerações que o precederam. A estas deve a civilização de que goza: a ciência, os inventos e processos de tôda ordem de que se serve, sem falar na parcela do capital já formada e depositada em suas mãos. Aos contemporâneos deve, afinal, a assistência e o concurso sem os quais, por maior que seja a sua capacidade, nada conseguiria. O capital é, portanto, indiscutìvelmente, de formação coletiva ou social, nele preponderando, ainda mais do que a solidariedade, a continuidade histórica.

Mas, não é só a riqueza. Também o trabalho é social em sua origem, constituindo a capacidade profissional de cada qual lenta e difícil criação da Humanidade, havendo exigido esforços que muitas vêzes remontam às primeiras etapas da história. Assim sendo, não deve o trabalho ter um destino exclusivamente pessoal, porquan-

(22). - Sāo Paulo: 1a. "ad Corinth", VII, 29, 30 e 31.

(23). - Vide Emet John Hugues: "Áscensão e decadência da burguesia", pg. 33 da trad. brasileira. 
to representa o contingente com que cada qual contribui para o bem-estar geral da coletividade, de quem tudo recebe (24).

Não admitindo, pois, dúvida serem a "riqueza" e o "trabalho" sociais em sua origem, daí decorre a exigência de o serem também em seu destino. E', portanto, sob o prisma social e relativo que devem ser encarados quaisquer direitos, até mesmo aquêle que, à primeira vista, parece ser o mais caracteristicamente individual e absoluto - o da propriedade.

Apresentados, entretanto, sob êste prisma social e relativo, de tal modo se tornam incontestáveis os direitos da personalidade humana que, sem serem respeitados, não subsistiria a própria sociedade à vista do aniqüilamento da dignidade fundamental do seu elemento indispensável - 0 indivíduo. Eis por que Brunetière, o famoso escritor e crítico literário, membro da Academia Francesa, declarava, apesar de católico militante, que desejava fôssem gravadas, nas paredes das escolas, ao lado da "Declaração dos Direitos do Homem", as considerações de Augusto Comte sôbre a relativação e socialização do direito (25).

Que a evolução do direito se tenha feito, dia a dia mais claramente, no sentido apontado pelo grande filósofo, é o que comprovam inúmeros publicistas modernos, entre os quais podemos citar, em França, Josserand, Duguit, Aubry e Rau, Capitant, Edmond Picard, Carré de Malberg, Georges Ripert, René Demogue, Henri e Leon Mazeaud; na Itália, Cogliolo e Grandi; na Espanha, Calvo Sotelo e Ascárate; no Brasil Philadelpho de Azevedo, Carvalho Santos, Virgílio de Sá Pereira, Eduardo Espínola, J. A. Nogueira, Miguel Reale, San Tiago Dantas, Noé Azevedo, Benjamin de Oliveira Filho e muitos outros.

A mudança profunda, assinalada por Augusto Comte na concepção do direito, consistindo, no dizer de jovem jurista brasileiro, "na socialização moralizadora do direito" (26), foi assim caracterizada, em 1919, pelo grande Rui Barbosa:

"A concepção individualista dos direitos humanos tem evoluído ràpidamente, com os tremendos sucessos dês. te século, para uma transformação incomensurável nas noções jurídicas do individualismo, restringidas agora por uma extensão, cada vez maior, dos direitos sociais. Já

\footnotetext{
(24). - Vide Pierre Laffite: "De la stabilité de l'équilibre économique", in Revue "La Politique Positive", t. I, pg. 148.

(25). - Ferdinand Brunetière: "Sur les chemins de la croyance - première étape: l'utilisation du Positivisme", pg. 261, Paris, 1905.

(26). - Edmundo Lins Neto, op. cit., pg. 26.
} 
Se não vê na sociedade um mero agregado, uma justaposição de unidades individuais, acasteladas cada qual no seu direito intratável, mas uma entidade naturalmente orgânica, em que a esfera do individuo tem por limites inevitáveis, de todos os lados, a coletividade. O direito vai cedendo à moral, o indivíduo à associação, o egoísmo à solidariedade humana" (27).

IVAN LINS

(27). - Rui Barbosa: "Teoria Politica", antologia prefaciada por Homero Pires, Jackon ed., Rio, 1950, pg. 17. 